sciendo

\title{
THE ROLE OF VOLUNTEERING IN THE INTEGRATION OF ROMA CHILDREN IN SCHOOLS-LESSONS FOR THE REPUBLIC OF NORTH MACEDONIA
}

\author{
Merita Zulfiu Alili \\ Faculty of Contemporary Social Sciences, South East European University, Republic of North \\ Macedonia \\ m.zulfiu@seeu.edu.mk \\ Veli Kreci \\ Faculty of Contemporary Social Sciences, South East European University, Republic of North \\ Macedonia \\ v.kreci@seeu.edu.mk \\ Alexander Krauss \\ Institut für sozialwissenschaftliche Beratung Regensburg, Germany \\ krauss@isob-regensburg.net \\ Nada Trunk \\ International School for Social and Business Studies, Slovenia \\ trunk.nada@gmail.com
}

\begin{abstract}
Education (good teachers and good schools) is crucial for the successful integration of vulnerable groups in the society. Multicultural diversity presents an opportunity to make schools more inclusive, creative and open-minded. Although there are different projects and activities for Roma inclusion in schools, the number of Roma children attending formal education is still very low. Without having attended formal education, the chances for social exclusion are high and minimal for leading a self-defined life. To increase the rate of school registration and the rate for completion, long-term policy interventions and financial support from international donations are needed. This paper aims to analyze the general situation of Roma children and youth the age of pre-school education, primary and secondary education, as well as the engagement of youth in volunteering activities as a significant role in the inclusion of Roma children in schools. Engagement in volunteering activities can help young people to be more integrated into society, as through volunteering they gain valuable experiences, new
\end{abstract}


skills, and competencies that can improve their employability possibilities and enhance their attitudes towards citizenship.

Key words: integration, education, volunteering.

\section{INTRODUCTION}

Roma children in North Macedonia are still on the margins of social life. There are still many of them who are not registered in the birth register (so- called "children - phantoms"); they are faced with lack of access to health services; and they face segregation in schools and increased school dropouts. Furthermore, they have inadequate housing, as an indirect factor of the low employment rate of their parents. Many Roma children are unaccompanied, they can be found on the streets begging or selling items such as wet wipes etc; most probably they make part of an elaborate human trafficking network operating locally and internationally. According to (CAHROM, 2015) the enrolment of Roma children in all levels of education is 20 to $30 \%$ lower than among non-Roma and the dropout rate of children is two times higher among Roma in comparison to non-Roma children. Pre-school education is not compulsory in North Macedonia. However, a project called «Inclusion of Roma children in preschool education» implemented by the Ministry of Labour and Social Policy and supported by the Roma Education Fund, is implemented in 18 municipalities to provide pre-school education for Roma children (CAHROM, 2015). In addition, in Topana, Skopje's second-biggest Romani neighborhood, the education and community development organization Sumnal helps 94 children attend preschool and runs workshops designed to help mothers prepare their kids for school (Petrovski, 2013). Although there are different projects and activities for Roma inclusion in pre-school education, the number of Roma children aged 0-6 years attending pre-school education is still very low. In the academic year 2009/2010, 20,317 children (of all nationalities) aged 0-6 years were enrolled in 52 kindergartens; 454 or $2.23 \%$ of them were Roma children. In the academic year 2010/2011, there were 23,503 children (of all nationalities); 551 or $2.34 \%$ of them were Roma children. In the academic year 2011/2012, there were 25,200 children (of all nationalities); about 600 or $2.38 \%$ of them were Roma children (CAHROM, 2015). In 2017, the adjusted net pre-primary enrolment rate for ages 3-6 was just 14 percent for Roma children, a rate 15 percentage points lower than that among neighbouring non-Roma, and 10 percentage points lower than in 2011 (UNDP and THE WORLD BANK, 2018). 
Unlike pre-school education, primary and secondary education is mandatory and is considered to be mainly the state's responsibility. Therefore, there are fewer projects for Roma inclusion in primary schools. However, Roma are better represented in primary school compared to preschool education. According to the Ministry of Education and Science, during the academic year 2011/2012, the number of Roma children who attended primary school was 9,924. UNICEF estimated in 2011 that only 63 percent of Romani 7-year-olds were enrolled in school, compared to 86 percent in the poorest households overall (Roma Transitions, 2013). According to education attendance date, the share of Roma children aged 6 attending pre-school education is $23 \%$, primary education $47 \%$ and not attending any kind of institutional education is $31 \%$ (UNDP, 2012). In Shuto Orizari, where the Roma population is mainly concentrated, there are two primary schools. Braka Ramiz and 26 July. In order to accommodate 2,300 pupils (about three times the intended capacity) classes are held in three shifts at Braka Ramiz and in two shifts at 26 July (Petrovski, 2013). Figure 1 shows school attendance by age groups in North Macedonia in 2011, comparing the share of Roma and non-Roma living in close proximity to Roma households. Differences in attendance between Roma and non-Roma are statistically significant for the age cohorts 10 to 12 and above (UNDP, 2012). In terms of attendance, the Roma seem to be strongly disadvantaged after the age of 18 , with the end of compulsory schooling.

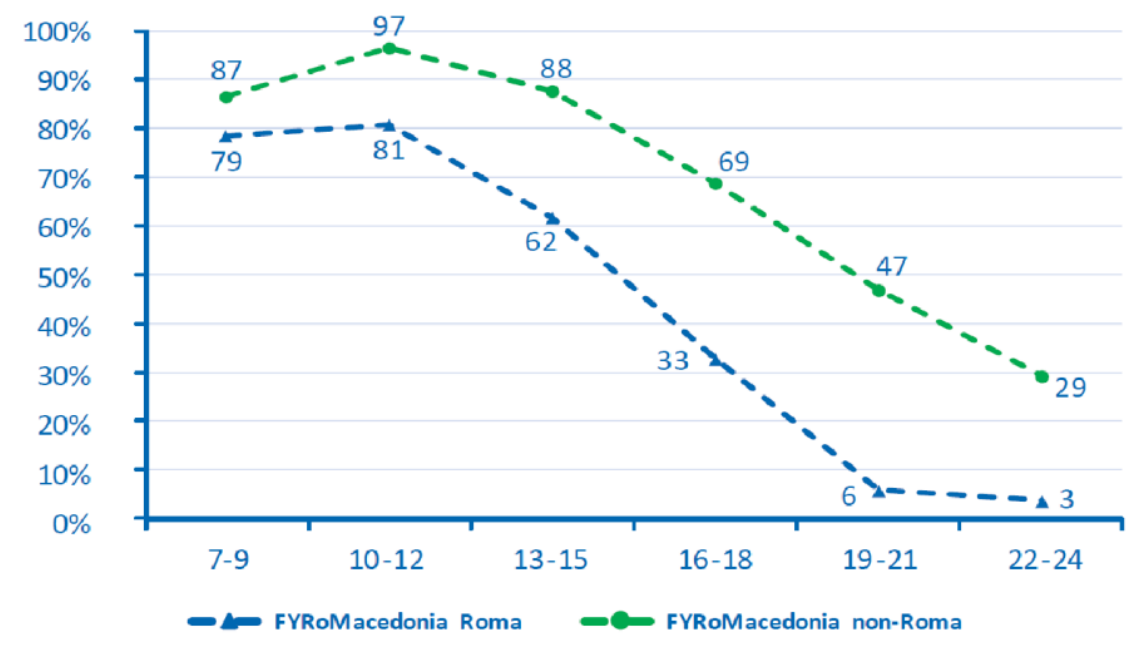

Figure 1. School attendance by age groups

Source: UNDP/World Bank/EC Regional Roma Survey 2011 (UNDP, 2012). 
According to the (Ombudsman of Republic of North Macedonia, 2018), Figure 2a, the highest number of enrolment of Roma students was in the school year 2008/2009, a total of 10187 students, while the smallest number of Roma students was enrolled in the school year 2015/2016, a total of 8785 students. In the period from 2005 to 2017 the percentage of nonenrolled students in upper secondary education has changed from year to year and the average of non-enrolled students was $30 \%$. The highest enrollment in secondary education was in the 2008/2009 school year when secondary education became compulsory. In that school year only $5 \%$ of Roma students who completed their primary education were not enrolled in secondary education (Figure 2b). So far this year has had the highest percentage of Roma children enrolled in secondary education. Unlike the school year 2008/2009, in the school year 2013/2014 it is noticeable that $65 \%$ of the Roma students who were in the last grade of primary education did not enrol in secondary education (Figure $2 b$ ). The average drop-out rate from one to another school year in the period from 2005/2006 to 2016/2017 ranges between 6-8\% in primary education. However, if we consider the 2008/2009 school year as basic year with a total of 1643 Roma students enrolled in the first year-comparing with the 2016/2017 school year with 747 Roma students enrolled in the ninth grade (full cycle from first to ninth grade) - it can be concluded that $60 \%$ of the generation 2008/2009 did not complete on time or left the educational process (Ombudsman of Republic of North Macedonia, 2018).

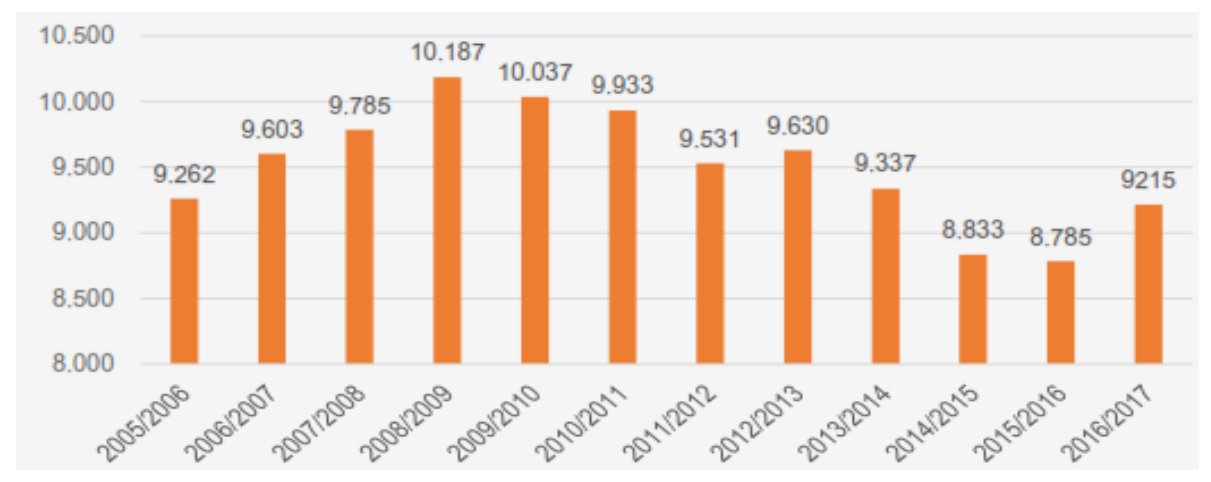

Figure 2a. Number of Roma pupils in elementary education

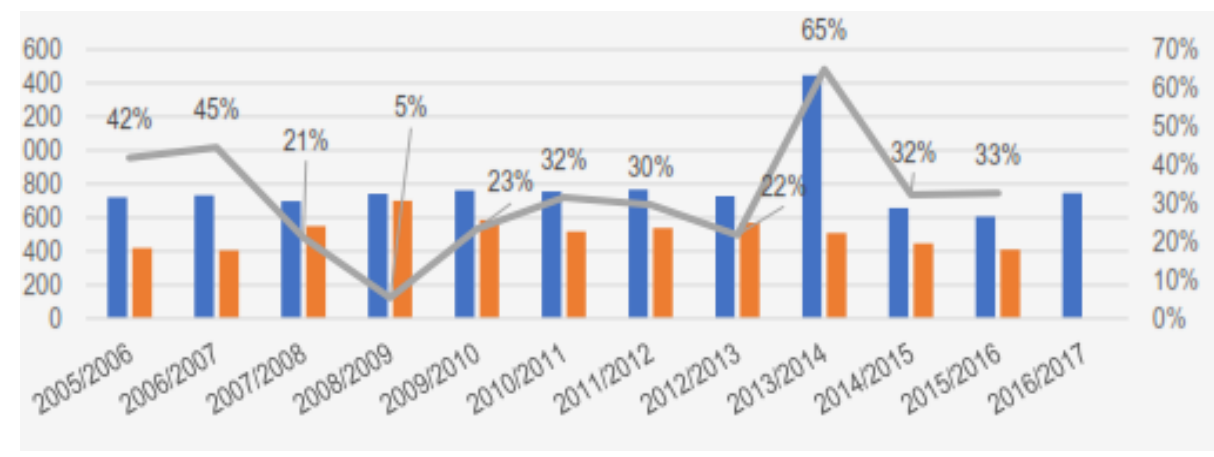


Figure 2b. Transfer of Roma pupils from elementary to high school

Number of Roma pupils in the final year of primary education

Number of Roma pupils enrolled in first year of secondary education

Percentage of unregistered Roma pupils in secondary education

Source: OMBUDSMAN of Republic of North Macedonia presentation: Roma inclusion after the decade of Roma-current situation and challenges, 2018.

Roma attendance in high schools has increased from 300 to 1,700 in less than two decades (Petrovski, 2013). As data in Figure 3a show, on average, 39\% of Roma high school pupils were enrolled in higher education, while $61 \%$ did not continue their education in the period from 2005 to 2017. The academic year 2009/2010 had the lowest percentage of non-enrolled Roma high school pupils in higher education, namely $49 \%$ of high school pupils did not enroll at university. However the percentage of non-enrolled Roma secondary education pupils to higher education has increased over years and especially in the academic year 2015/2016 reaching $73 \%$ of unregistered students (Figure $3 \mathrm{~b}$ ). The average drop-out rate from one to another school year in the period from 2005/2006 to 2016/2017 was $15 \%$ in secondary education (Ombudsman of Republic of North Macedonia, 2018).

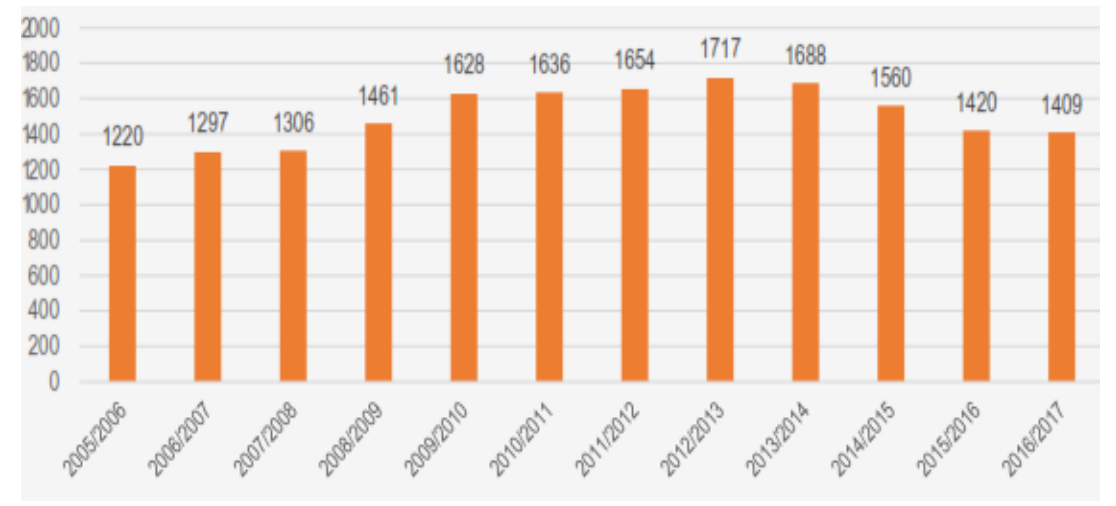

Figure 3a. Number of Roma pupils in secondary education

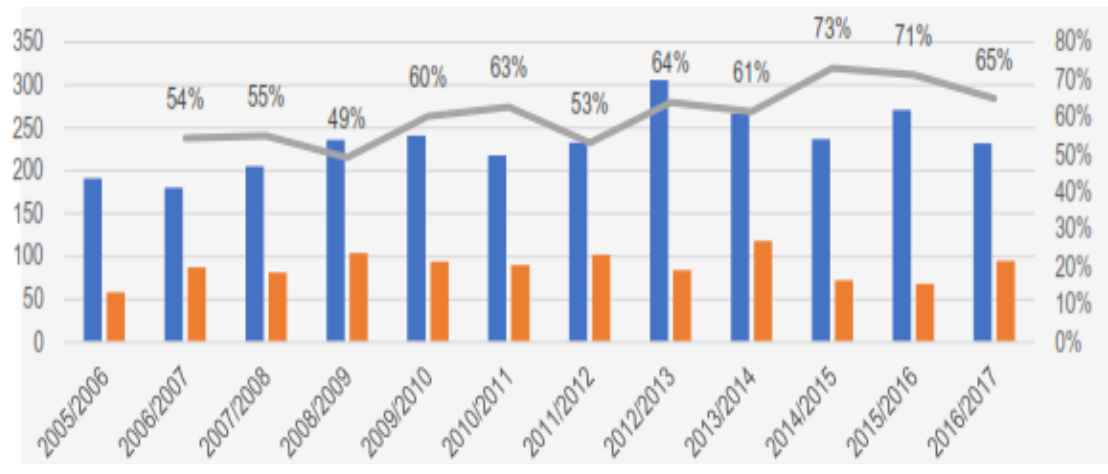

Figure 3b. Transfer of Roma pupils from high school to university

Number of Roma pupils in the final year of primary education 
Number of Roma pupils enrolled in first year of secondary education

Percentage of unregistered Roma pupils in secondary education

Source: OMBUDSMAN of Republic of North Macedonia presentation: Roma inclusion after the decade of Roma-current situation and challenges, 2018.

Free public transport, scholarships and mentoring programs - developed by the Ministry of Education and Science and the Open Society Foundation-have been since 2009 the most effective measures in helping the Roma inclusion progress. There is a 57\% increase of high school pupils through different Roma inclusion programs from 2005 to 2017. From 2005 OSF scholarships have been available for Roma students and from 2009 the Ministry of Education has provided 600 scholarships for the inclusion of Roma children in high schools for the 1st and 2 nd grade, whereas for the 3rd and 4th year the mentoring system was provided.

A lot has been done in the fields of education of Roma. More than 2500 scholarships have been provided to high school and university students for several generations of Roma students and for students who attained formal education. Currently some of them are holding high level management positions in the public administration, with authority to decide on policies related to the Roma community (this initiative was implemented by Open Society Foundation in North Macedonia (OSFM) and was later was adopted by the Ministry of Education and Science). There also exist non-formal centers run by Roma NGOs providing direct educational afterschool support (which has a compensatory role) through money from international donations.

The rest of the paper is organized as follows. The following section describes the problematic phenomena about primary and secondary school attendance of Roma children whilst the role of voluntary work/engagement of civil society in mitigating the problem is explained in the third section. The results of the training for volunteers are presented in the fourth section. The final section summarizes the key findings and considers their implications for policy.

\section{PROBLEMATIC PHENOMENA ABOUT PRIMARY AND SECONDARY SCHOOL ATTENDANCE OF ROMA CHILDREN}

The rate of irregular attendance and the dropout rate of Roma children is high both in primary and secondary education. The Roma that attend school indicate higher absences in comparison to their non-Roma peers, which puts students at risk of dropout (UNDP, 2012). A considerable share of young Roma in North Macedonia has never been to school. About one out of ten Roma age 10-18 is without school experience (UNDP, 2012). Without having attended formal 
education, the chances for social exclusion are high and minimal for leading a self-defined life (UNDP, 2012).

A recent study ${ }^{1}$ of the Roma Resource Center and the Center for Family Care-Atina have found that the main reasons for high school drop-out in Roma children is due to skipping pre-school education; low education and social status of parents; poor knowledge of the Macedonian language; and low school attendance. These phenomena are problematic, as discussed in the literature about primary and secondary low school attendance along with above findings and the points listed as below (CAHROM, 2015; Petrovski, 2013):

1. The low awareness of Roma families about the importance of enrolling their children in schools.

2. Low capacities and poor conditions in schools.

3. The fact that children speak Romani at home and have little knowledge of the Macedonian language. The North Macedonian educational system does not yet provide tuition in Romani, which for many Roma is their first language.

4. The fact that most Roma continue to live in settlements isolated from the rest of society (European Roma and Travellers Forum, 2015).

5. Living on a very limited budget and, therefore, not being able to pay school expenses.

6. An unfriendly school environment for Roma where they are subject to prejudice and exclusion very often due to lack of cultural sensitivity.

7. Inability to travel to school also affects regular attendance.

According to the Roma Education Fund (2007), the most important problems threatening the quality of the education of Roma in North Macedonia are the following (p.10-11):

1. There is virtually no social support promoting wider participation in education.

2. State-provided education is, to a considerable extent, complemented by nongovernmental organizations, which are financed through grants by the international donor community. 
3. Administrative barriers for enrolling into pre-school and primary education still exist, given that many Roma families lack necessary documentation and social support from the state. The announced partial privatization of pre-school institutions and the consequences to be introduced might further jeopardize the access of Roma to preschool.

4. Segregation in special schools and separate classes is still common in North Macedonia, and there is not much reaction to this problem - even from the Roma communities.

5. Despite supportive policies, schools are generally unwelcoming and unsupportive of Roma children.

It also needs to be acknowledged that although legal segregation tends to diminish gradually, informal segregation has been on the rise because parents of non-Roma children withdraw their children from schools that become increasingly dominated by Roma children (European Roma and Travellers Forum, 2015).

The country is a member of the Decade of Roma Inclusion 2005-2015. The National Roma Integration Strategy (NRIS) was set up in 2012 and implemented from 2014 for a decade (European Roma and Travellers Forum, 2015). This strategy is covering major areas in which there are problems for the Roma community, such as health, schooling, employment, and housing. So far the strategy has been limited in terms of results but civil society actors have been very active in monitoring the process while pointing out areas for improvement. Namely, it has been pointed out that Roma in North Macedonia are excluded from different aspects of social and economic life, including employment, housing and education. Also, it has been noted that settlements continue to be isolated from rest of society, and lack of access to water supply, hate speech, and racism are still listed as common problems. 


\section{THE ROLE OF VOLUNTARY WORK/ENGAGEMENT OF CIVIL SOCIETY IN MITIGATING THE PROBLEM}

Civil society has been a great advocate of raising awareness of voluntary work in society through individual contribution by putting one's knowledge, skills, and values forward for the betterment of society. As part of these efforts the government has recognized the need to regulate voluntarism in North Macedonia. Therefore, the Law on Voluntarism was brought in 2008. Since then many amendments have been made as to respond to gaps during the implementation phase. According to Youth Wiki (2017, p.17) "only about $15 \%$ of the citizens volunteer in various activities and initiatives, and only $10 \%$ volunteer in civic organizations despite encouraging legal and fiscal framework for volunteering. Citizens do not have continuity in voluntary activities: a total of 10 volunteer hours a year on various unrelated objectives / activities. Therefore, it is important to continue to raise awareness among citizens, especially young people about the opportunities and benefits that civil society provides in order to encourage their active participation and the importance of monitoring and participation in policy and decision making".

In regard to the integration challenges of Roma children, civil society organizations through their voluntary activities have been engaged in working with children. North Macedonia is one of few countries where civil society organizations of Roma are great in numbers and very active in their activities. Namely, the Roma Resource Center (RRC) is one of few civil society organizations that provides diverse activities to Roma children for their personal development on a voluntary basis. Their activities range from health issues within Roma dominated area to employment of high school and university graduates. Regular workshops and after school activities are organized by RRC by setting an example to other civil society organizations to follow. In terms of identifying good practices, the following have been selected:

1. After school workshop for Roma children. Students of primary school attend afterschool sessions for getting help with their homework and understanding school materials better.

2. Organized workshops by Roma alumni to secondary education students. Motivating students to start thinking about their future and deal with social inclusion at early stages.

3. Organizing regular visits to social places and institutions. Getting students familiar with social institutions performing out of their neighborhood or at large in society. 


\section{TRAINING FOR VOLUNTEERS AND VOLUNTEERING ACTIVITIES}

Using the RoMIGSc data from the training for volunteers and volunteer activities organized in 2018 and 2019, this paper aims at acknowledging the importance of volunteering for social inclusion of the Roma population in North Macedonia ${ }^{2}$. Training for volunteers was organized in two locations: Skopje and Tetovo, where 47 participants attended the training. The group of participants was very diverse; from senior high school students to school teachers and professional volunteers. Sessions covering critical themes of volunteering work were delivered by 6 national and international speakers.

We claim that volunteering experiences are crucial for social inclusion of both groups: volunteers on one side, and beneficiaries of volunteering activities on the other side. Roma children and their parents are the groups that volunteers will help. Our filed work shows that even if children go to school, some of the major problems still exist: that they do not do regular homework, their parents have low education, and they do not encourage children to engage in school (low expectations). Volunteers can thus help Roma children with their school work, as well as to help their parents to integrate better into the community. Populations with a low level of school routine and socialization need other learning arrangements. As we observe, e.g. the requirement to do homework in a self-organized way can only be introduced gradually. A higher level of supportive and structured learning environments is needed in the beginning. Volunteers can be crucial supporters here.

The aim of the training for volunteers was to give participants an opportunity to develop knowledge, skills and attitudes to assess needs for volunteering and to develop a program for volunteer activity. In addition, it was intended to prepare volunteers for engagement in volunteering in the period from March to June/July 2018 and February to June/July 2019.

\section{EVALUATION OF THE TRAINING AND POLICY RECOMMENDATION}

The questionnaire prepared in national languages was hand delivered after the training with instructions that the questionnaire is anonymous and that they should take enough time to provide as much feedback as possible. All participants (29 in 2018 and 24 in 2019) filled out the questionnaire and, based on the responses, analysis is provided below.

\footnotetext{
2 see the RoMigSc project website for more information about the project (https://romigsc.eu/).
} 
Summary of training evaluation (2018):

1. The majority of respondents were students $(48 \%)$ and female $(66 \%)$.

2. Most of the respondents have been involved in volunteering work (57\%) and have experience with the Roma population.

3. The respondents were quite satisfied with the training. They were especially satisfied with the discussions about the integration of Roma children in schools.

4. Participants were mostly satisfied with the opportunities to express their suggestions and opinions during the event $(51 \%)$ and with their perception of obtaining new knowledge (49\%).

Summary of training evaluation (2019):

1. The majority of participants were students (42\%) and male (54\%).

2. $29 \%$ of respondents had experience with the Roma population and $21 \%$ have been involved in volunteering work.

3. The respondents were quite satisfied with the training, and especially satisfied with the discussions about the integration of Roma children in schools.

4. Participants were mostly satisfied with the opportunities to express their suggestions and opinions during the event as well as with their perception of obtaining new knowledge (88\% vs. $83 \%)$.

\section{LESSONS LEARNED AT THE SEMINAR}

We also asked the participants about the most valuable lessons they learned during the seminars. Here are the examples stated in the survey:

1. what is volunteering and experiences of volunteers;

2. a pleasure to help society through volunteer activities;

3. volunteering is important for our society and our self-development;

4. not to give up and continue helping;

5. how to volunteer and where; 
6. motivation of participants/students to get involved in volunteering activities;

7. encouragement and motivation about volunteering.

\section{VOLUNTEERING ACTIVITIES}

Volunteering activity covered large area of vulnerable groups' neighbourhood. Approximately 400 children received assistance or were involved directly in activities organized by volunteers. Mentors at a school or NGO with diverse background worked directly with volunteers to conduct volunteering activities. More than 20 institutions and organizations were recipients of volunteering work, where primary and secondary schools; NGOs; social institutions were primary target group of volunteering activity. During February 2018 until September 2019, 38 volunteers actively performed and 4399 hours of volunteering work were delivered. Volunteering work was performed as small school projects in the field of the integration of Roma children, such as:

1. Learning assistance to pupils in Macedonian language, math and other subjects.

2. Creative workshops for interconnecting and spending qualitative spare time.

3. Visiting parents of children with problems in schools.

4. Participation in sports, cultural days and other activities.

5. Preparing high school pupils for the state Matura exam.

6. Socializing with Roma children during morning care, drawing, telling stories etc.

Personal benefits the volunteers experienced through volunteering:

1. Opportunity to gain new experiences, skills and competencies, such as: empathy, feeling good for helping others, motivation and inspiration for further volunteering activities, learning to work in a team, community experience.

2. Respondents felt that this experience had an important impact on their personal and professional growth.

Benefits for beneficiaries of volunteering help and for host institutions:

1. Beneficiaries benefited from informal \& spontaneous contacts with volunteers, which facilitated their integration within society. 
2. Volunteers used storytelling and drawing, which were popular.

3. Volunteers helped in overcoming social and cultural barriers of beneficiaries; through several activities (Macedonian language, help in other courses such as math, geography etc, storytelling, different social \& cultural activities, other activities for social inclusion ...) which helped beneficiaries to feel more confident and succeed in passing exams or having good marks.

4. Volunteers enriched regular activities of their host institution.

Benefits for community/society:

1. Volunteering as additional help for dealing with integration (in a more spontaneous way)

2. Such work raises respect for cultural diversity in the region; importance of solidarity, respect/care for others.

3. Assistance to Roma children, youth and parents.

4. Assistance to teachers, as there are often too few staff at the schools.

5. Connecting with the community.

6. The volunteer made it easier for teachers to work, as he/she was actively involved in learning assistance.

7. Help to integrate and improve student grades.

8. Make teachers' work more comfortable.

9. Additional help to provide learning assistance to the children who need it.

10. Helping vulnerable groups in society.

11. High motivation (students, volunteers).

12. Extra help to children who need it.

\section{POLICY RECOMMENDATIONS}

In countries like the Republic of North Macedonia-a multicultural society where the coexistence of different ethnic groups proceeds through multilingual education at early ages of 
schooling - understanding and living within an environment of cultural differences has been key challenge in designing a successful school system to achieve social cohesion. Within this schooling system, the integration of disadvantaged social groups requires additional initiatives supported by local, national and international representatives. From the evaluations given by the participants, we can extract the following (policy) recommendations:

1. Lack of multi- and trans-cultural awareness can result in discriminatory practices, intended or unintended. Therefore training in diversity awareness should be expanded.

2. Systemic and continuous long-term solutions should be initiated to support inclusion and better learning opportunities for Roma children. These should follow holistic, longterm strategies, which include factors of social stabilization, acceptance and inclusion as well as encouragement of Roma Community self-organization.

3. More intensive work with the parents of Roma children is needed.

4. Prejudices, stereotypes, insufficient understandings of the diversities in society are considered also as obstacles for the inclusion of Roma children in schools.

5. Roma children need to learn the Roma language as a course in primary schools.

6. Special programs are needed and applied in some cases for pupils who cannot write and read.

7. Introduction of courses at university level to promote voluntary activity based on ECTS.

8. There is a need for inclusion of more volunteers, debates, and training for the integration of Roma children in schools.

9. More promotion (seminars like this, through the education system and NGOs) on volunteering activities among pupils and students.

\section{CONCLUSION}

Legislation includes Roma children in all areas of social life. There are laws governing their right to education, health care, social protection, etc. However, the legal regulations are not fully respected, which is particularly evident in the existence of unregistered children in the birth register, the phenomenon of discrimination and segregation in the schools, as well as lack of access to health services. Project experiences of the OSFM demonstrated that if one has all conditions for learning and systems for support Roma children can equally advance in school 
as their peers. Lack of knowledge of the Macedonian language before school, financial conditions, inadequate environment for learning, stereotypes, inadequate training for teachers who work with children of vulnerable groups are very often limitations for good school results and advancement in career. Awareness in parents is substantially changed and they very well understand the importance of education. But there are still early marriages, ghettoized neighborhoods, and high dropout rates from schools.

Education must be a primary priority because it creates good practices in Roma education. For example, through providing medical scholarships, there are now Roma doctors and/or medical staff, which was not the case before, as well as lawyers, economists and social workers. It is recommended that volunteerism must be recognized by all levels of society as a value for building healthy societies. Media outlets, educational institutions, social institutions and government institutions shall play critical role in recognizing volunteerism and raising awareness for volunteerism. Civil society should be more accessible and innovative in their programs to invite a broader spectrum of individuals into their work and to represent their interests accordingly. There are different projects for inclusion of Roma children in pre-school and school education, such as free pre-school education, free public transport, one-time financial support for children registering to school to avoid street begging, scholarships, mentoring programs for students, etc. There exists a national strategy for Roma until 2020 which is inconsistent-identified problems are not fully corresponding with a set of perceived policies and measures for support — but it still provides a strategic framework for the state. In spite of systemic limitations (orientation, mental models, funding), there is a high level of engagement of schools, teachers and volunteers as well as some valid policies that can be part of more systemic future solutions. 


\section{REFERENCES}

- CAHROM. (2015). Thematic Report of the Group of Experts on Inclusive Pre-School Education for Roma Children. Strasbourg: Council of Europe.

- European Roma and Travellers Forum. (2015, September 10). http://www.ertf.org/. Retrieved from eurodiaconia.org: https://www.eurodiaconia.org/de/2015/09/fact-sheet-on-the-situation-ofroma/

- Ombudsman of Republic of North Macedonia. (2018). Roma inclusion after the decade of Romacurrent situation and challenges. Skopje: Ombudsman of Republic of North Macedonia.

Retrieved from http://ombudsman.mk/upload/documents/2018/Prezentacija-Inkluzija\%20RomiVrabotuvanje-07.11.2018.pdf

- Petrovski, D. (2013, March 4). In Macedonia, Dividends on Efforts to Keep Roma in School. Retrieved from chalkboard.tol.org: http://chalkboard.tol.org/in-macedonia-dividends-on-effortsto-keep-roma-in-school/

- Roma Education Fund. (2007). Advancing Education of Roma in Macedonia. Budapest: Roma Education Fund. Retrieved from https://www.romaeducationfund.org/wpcontent/uploads/2019/05/macedonia_report.pdf

- UNDP. (2012). Roma Education in Comparative Perspective. Findings from the UNDP/WORLD BANK/EC REGIONAL ROMA SURVEY. Roma Inclusion Working Papers UNDP Europe and the CIS Bratislava Regional Centre.

- UNDP and THE WORLD BANK. (2018). Roma at a Glance, The Former Yugoslav Republic of Macedonia. UNDP and THE WORLD BANK. Retrieved from https://www.eurasia.undp.org/content/rbec/en/home/library/roma/regional-roma-survey-2017country-fact-sheets.html

- Youth Wiki . (2017). Youth policies in the former Yugoslav Republic of Macedonia. European Commission. Retrieved from https://eacea.ec.europa.eu/nationalpolicies/sites/youthwiki/files/gdlformer_yugoslav_republic_of_macedonia.pdf 